\title{
Tri resonance multi slot patch antenna
}

\author{
Kemal Temur $^{1^{*}}$, Sehabeddin Taha Imeci ${ }^{2}$ \\ ${ }^{1,2}$ Department of Electrical and Electronics Engineering, International University of Sarajevo, Bosnia
}

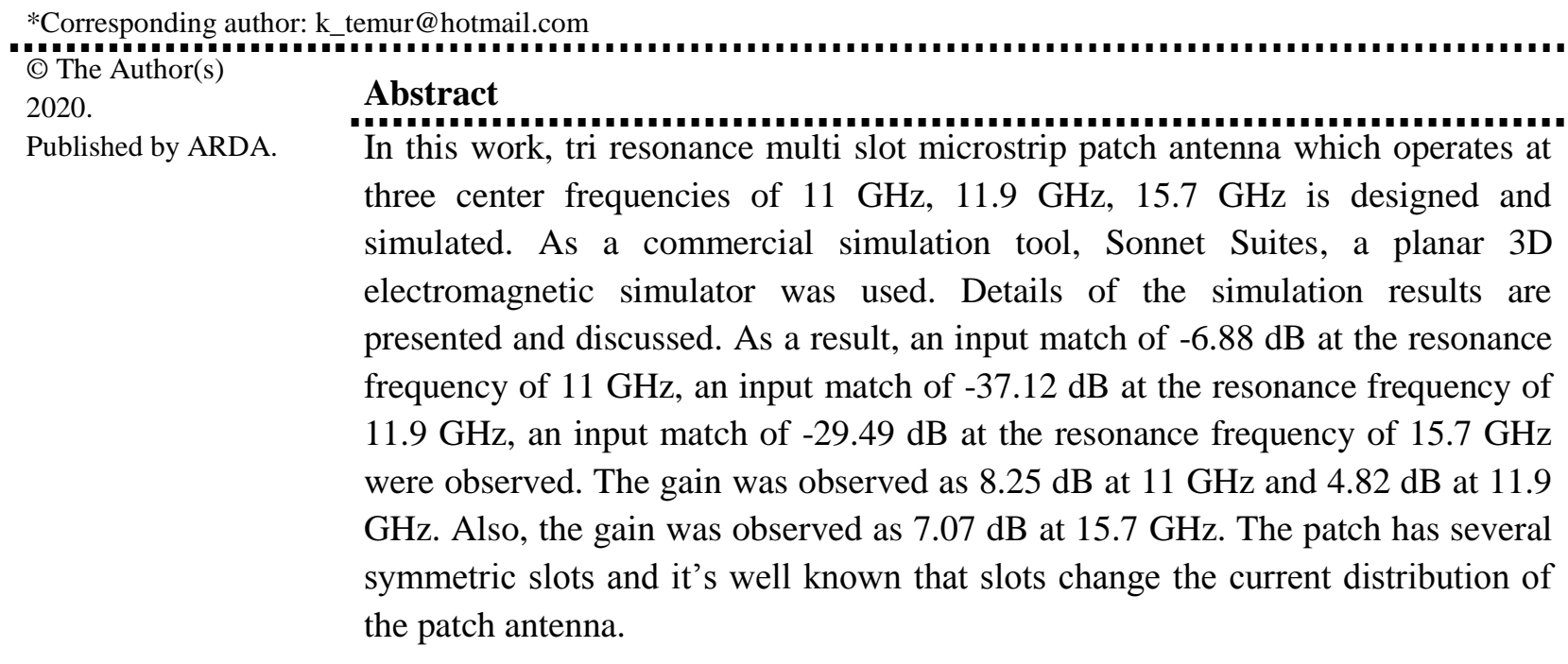

Keywords: Sonnet suites, Patch antenna, Multislot, Multi resonance

\section{Introduction}

Microstrip patch antenna has been studied in use for a long time. The demand for conformability, portability, low cost, light weight has increased. Microstrip antennas are attracting attention in broad range of multifunctional wireless communication systems [1]. The patch and the ground plane may have various geometric configurations and input impedances are usually $50 \Omega$ or $75 \Omega$. Thus, antennas that can operate at more than one frequency are desired. A single wide-band antenna may fulfill the requirement but on account of receiving more than one frequency band at the same time and consequently is prone to interference [2]. They have some limitations, especially narrow bandwidth. So different antennas that are needed for different applications will cause a limited space problem. Re-searchers think that multiband antennas provide solutions. A multi-band antenna can be made by changing the antenna shape [3]. There are numerous and well-known methods to increase the bandwidth of antennas, including increase of the substrate thickness, the use of a low dielectric substrate matching and feeding techniques, and the use of slot antenna geometry. Many techniques have been reported to reduce the size of microstrip antennas at a fixed operating [4]. These periodic structures would allow a single patch antenna to resonate at multiple frequencies, so that by adjusting their number, shape, width and their positions with respect to each other within the patch, the selection of the desired set of bands is easily achieved. The main purpose is to design a microstrip patch antenna system in the range of 11 to $22 \mathrm{GHz}$ [5]. These different studies have been reported in the literature studies of antennas with different frequency and bandwidths.

\section{Antenna design}

In this section we will introduce the design of our antenna [6]. The effective dielectric constant has values in the range of $1<\varepsilon_{\text {reff }}$, where the dielectric constant of the substrate is much greater than the unity $\left(\varepsilon_{\text {reff }}\right\rangle$ $1)$, the value of $\varepsilon_{\text {reff }}$ will be closer to the value of the actual dielectric constant $\varepsilon_{\text {reff }}$ of the substrate. The various design equation for the conventional patch antenna is as written below [7]. 
The most desirable substrate for good antenna performance is normally thick substrate whereby the dielectric constant is at the lower end. This is due to the fact that this range provides better performance compared to thin substrate [8]. The width (W) and the length (L) of Antenna 1 are calculated from conventional equations:

$$
\begin{aligned}
& f_{r}=\frac{c}{2 w} \sqrt{\frac{2}{\left(1+\varepsilon_{r}\right.}} \\
& L=L_{e f f}-2 \Delta L
\end{aligned}
$$

where,

$$
\begin{gathered}
\frac{\Delta L}{h}=0.412 \frac{\left(\varepsilon_{r e f f}+0,3\right)\left(\frac{W}{h}+0,264\right)}{\left(\varepsilon_{r e f f}-0,258\right)\left(\frac{W}{h}+0,8\right)} \\
\varepsilon_{r e f f}=\frac{\left(\varepsilon_{r}+1\right)}{2}+\frac{\left(\varepsilon_{r}-1\right)}{2 \sqrt{\left(1+12 \frac{h}{w}\right)}} \\
L_{e f f}=\frac{c}{2 f_{r} \sqrt{\varepsilon_{r e f f}}}
\end{gathered}
$$

where,

$L_{e f f}$ is effective length of the patch,

$\frac{\Delta L}{h}$ is normalized extension of patch length,

$\varepsilon_{\text {reff }}$ is effective dielectric constant [9].

For efficient radiation, the width $W$ is given as:

$$
W=\frac{c}{2 f_{r} \sqrt{\frac{\left(\varepsilon_{r}+1\right)}{2}}}
$$

where,

$c$ is the speed of light and $W$ is width of patch antenna [10].

The geometry of the slot antenna is shown in Fig. 1. The size of the antenna is $48 \times 64 \mathrm{~mm}$. A dielectric substrate with dielectric permittivity $\varepsilon_{\text {reff }}$ " of 4.3 and thickness $h 1$ of $1 \mathrm{~mm}$ has been used in this design [11]. The antenna consists of square slots and rectangle slots. Also, the slot made on the ground helps in the reduction of overall weight and size of proposed antenna [12].

The position of the coaxial cable can be obtained by using the following equation:

$$
X_{f}=\frac{L}{\sqrt[2]{\varepsilon_{\text {reff }}}}
$$

where,

$X_{f}$ is the desire input impedance to match the coaxial cable

$$
Y_{f}=\frac{W}{2} \quad[13]
$$




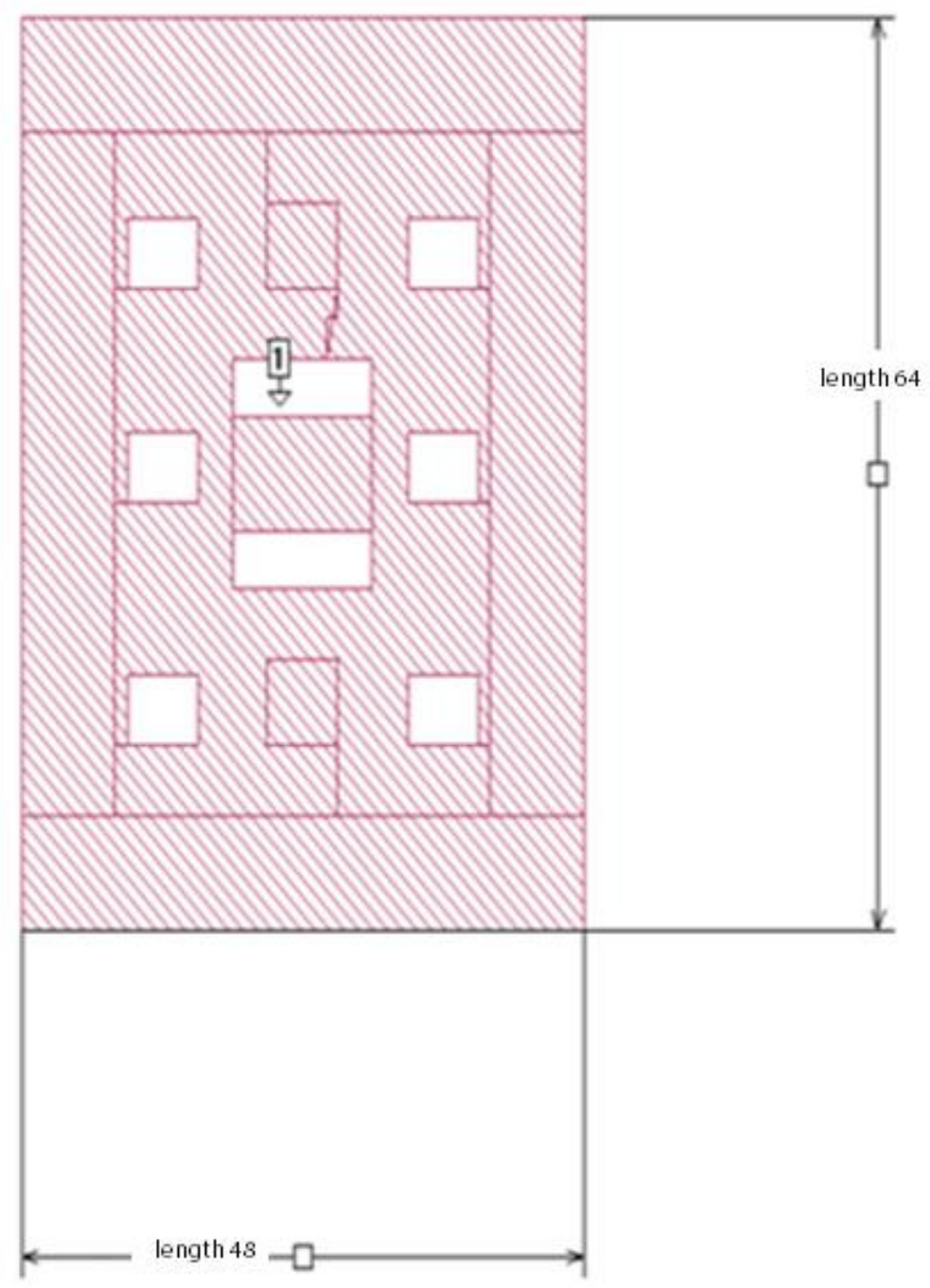

Figure 1. The top view of the antenna

\section{Analysis results}

The simulation and analysis are completed for tri resonance multi slot patch antenna by sonnet lite software. The model was designed to match $50 \mathrm{Ohm}$ of the corporate feed [14]. The input match is another way of expressing mismatch. It is a logarithmic ratio measured in $\mathrm{dB}$ that compares the power reflected by the antenna to the power that is fed into the antenna from the transmission line.

$$
\text { Input match }=20 \log _{10} \frac{S W R}{S W R}-1
$$

$S W R=$ Standing Wave Ratio [15].

The first important parameter which is helpful to calculate the bandwidth of the antenna structure is its S11 in decibel versus frequency. During this antenna feeding has been done at the point where the input match is minimized [16]. Input match as a result of simulations performed was observed as in Fig. 2. 


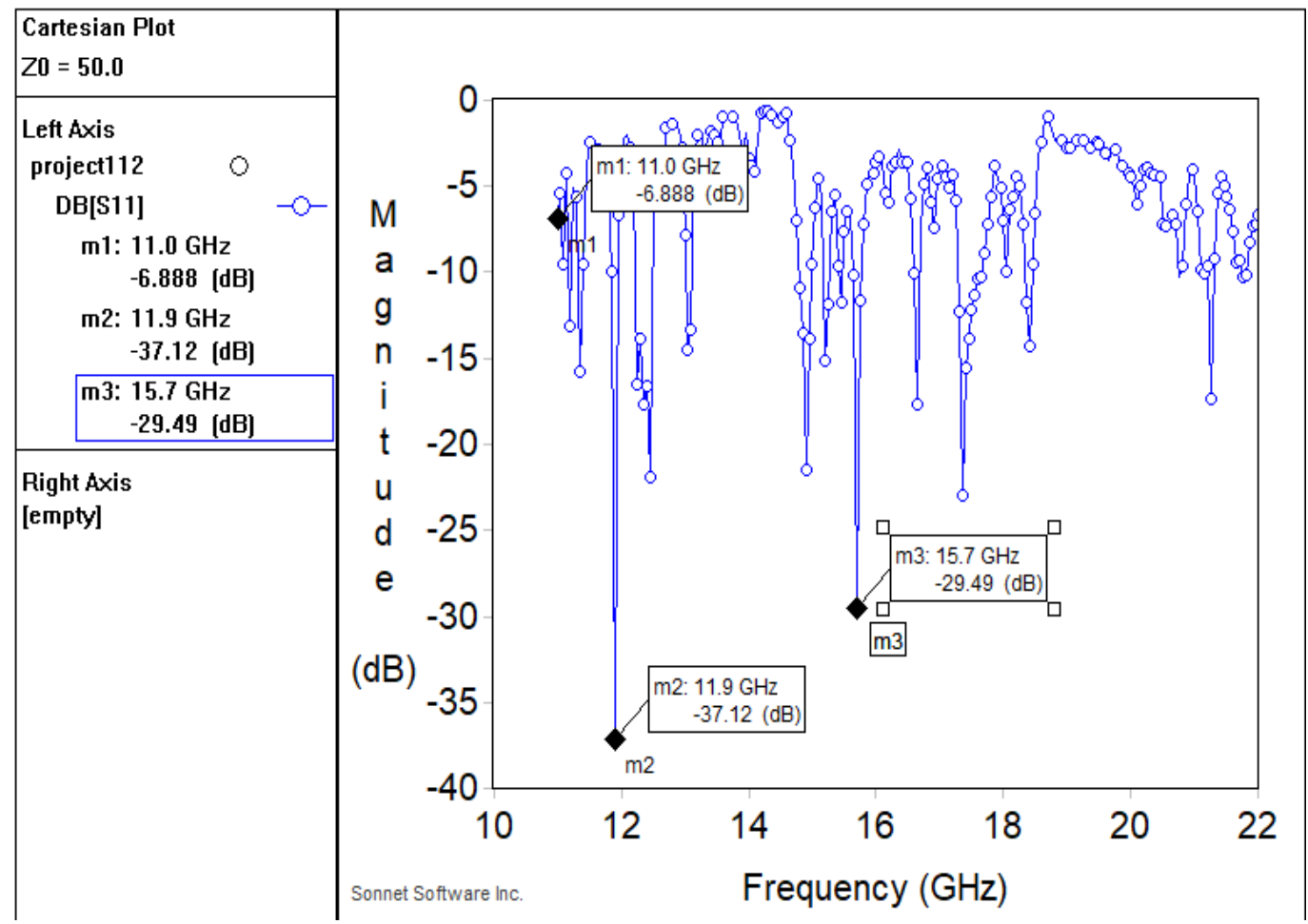

Figure 2. Input Match of the antenna

The simulated radiation patterns of the antenna at its resonance in the elevation-cut plane $\left(\phi=0^{\circ}\right.$ and $\phi=$ $90^{\circ}$ ) have been illustrated [17]. In frequency of $11 \mathrm{GHz}$, as it can be seen in Fig. 3, $8.25 \mathrm{~dB}$ directional gain at $\Theta=\mp 60^{\circ}$ was obtained in the electric field $\Theta$ polarization. Cross polarization level is less than $-5 \mathrm{~dB}$. In frequency of $11.9 \mathrm{GHz}$ with an input match value of $-37.12 \mathrm{~dB}$, as seen in Fig. 4, $4.82 \mathrm{~dB}$ directional gain was obtained in the electric field $\Theta$ polarization at $\Theta=45^{\circ}$. Cross polarization level is less than $-7 \mathrm{~dB}$.

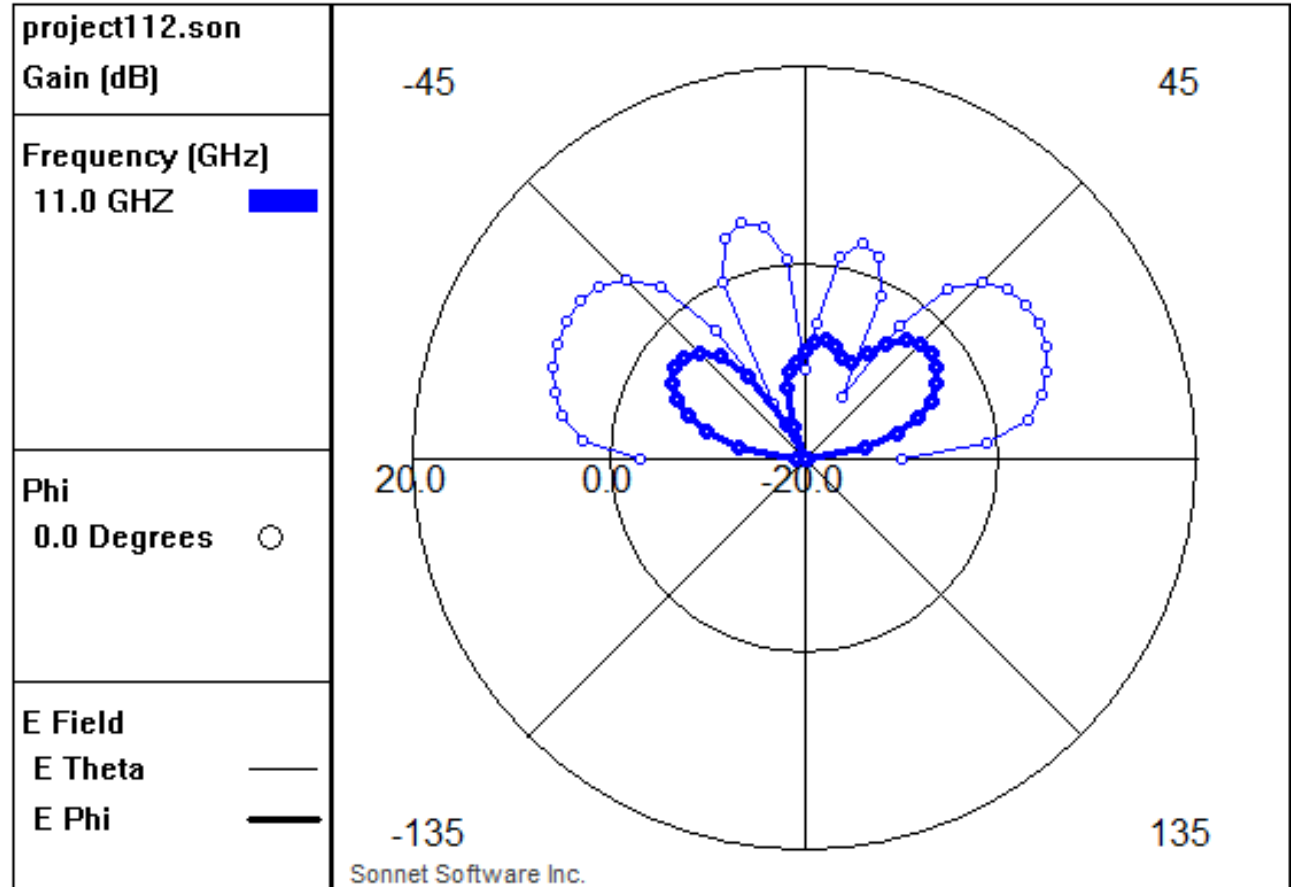

Figure 3. Radiation pattern of the antenna at $11 \mathrm{GHz}$

In frequency of $15.7 \mathrm{GHz}$ with an input match value of $-29.49 \mathrm{~dB}$, as seen in Fig. 5, there was a $7.077 \mathrm{~dB}$ directional gain at $\Theta=0^{\circ}$ in the electric field $\phi$ polarization. Cross polarization level is less than $-9 \mathrm{~dB}$. 


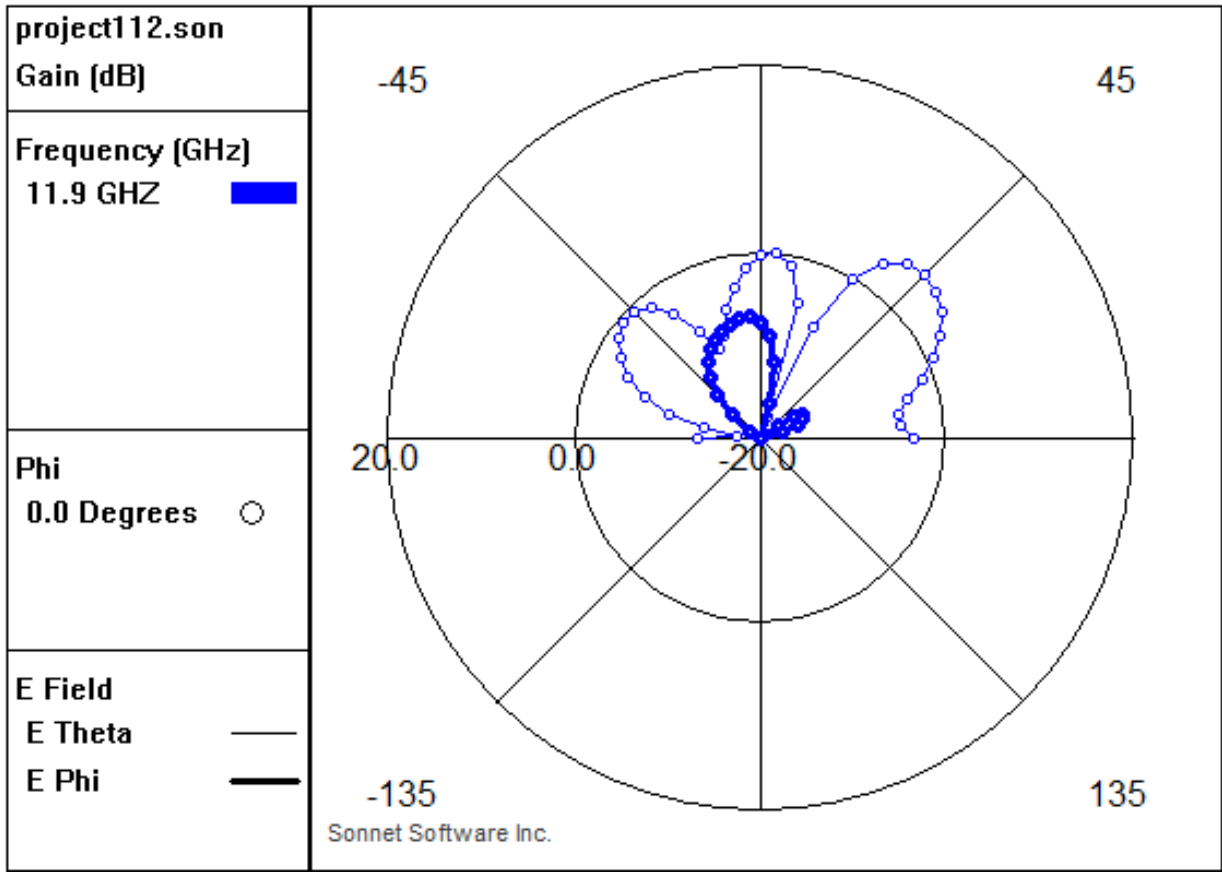

Figure 4. Radiation pattern of the antenna at $11.9 \mathrm{GHz}$

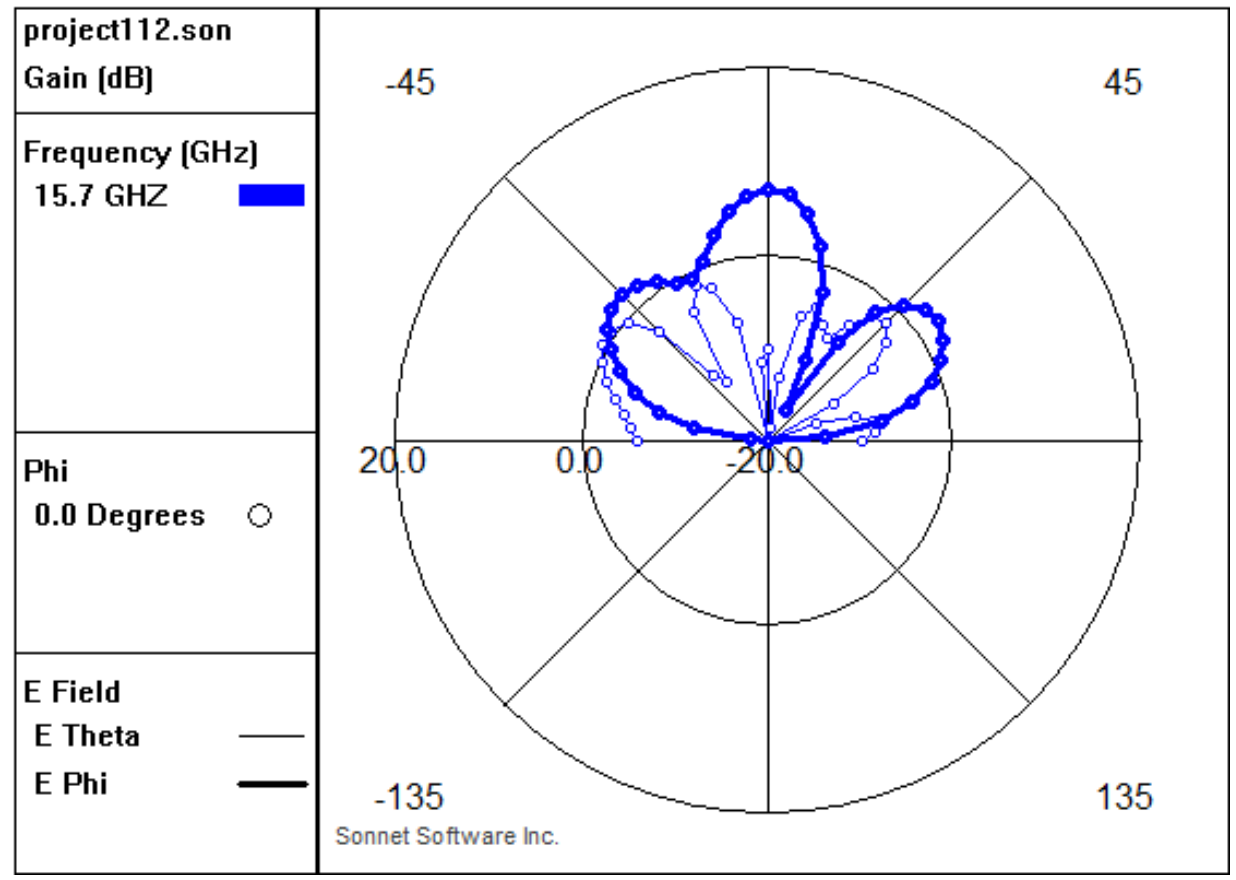

Figure 5. Radiation pattern of the antenna $15.7 \mathrm{GHz}$

A parametric study was conducted in order to see the fabrication tolerances of the antenna. The changes which are slot size, dielectric thickness, dielectric(air) thickness and dielectric constant, made in the patch geometry helped to improve design parameters such as return loss, gain, resonance frequency and impedance [18]. The optimization of the air layer thickness results is seen in Table 1.

Table 1. Optimization of the air layer thickness

\begin{tabular}{|c|c|c|c|}
\hline $\begin{array}{c}\text { Air thickness } \\
(\mathrm{mm})\end{array}$ & $\begin{array}{c}\text { Magnitude } \\
(\mathrm{S} 11: \mathrm{dB})\end{array}$ & $\begin{array}{c}\text { Resonance } \\
\text { Freq.(GHz) }\end{array}$ & Gain(dB) \\
\hline & -6.88 & 11 & 8.25 \\
\hline
\end{tabular}




\begin{tabular}{|c|c|c|c|}
\hline $\begin{array}{c}\text { Air thickness } \\
(\mathrm{mm})\end{array}$ & $\begin{array}{c}\text { Magnitude } \\
(\mathrm{S} 11: \mathrm{dB})\end{array}$ & $\begin{array}{c}\text { Resonance } \\
\text { Freq.(GHz) }\end{array}$ & Gain(dB) \\
\hline \multirow{2}{*}{11} & -37.12 & 11.9 & 4.82 \\
\cline { 2 - 4 } & -29.49 & 15.7 & 7.07 \\
\hline \multirow{3}{*}{11.25} & -5.44 & 11 & 8.24 \\
\cline { 2 - 4 } & -39.02 & 11.9 & 4.85 \\
\cline { 2 - 4 } & -29.95 & 15.7 & 8.0821 \\
\cline { 2 - 4 } & -6.79 & 11 & 4.865 \\
\cline { 2 - 4 } & -39.42 & 11,9 & 7.0828 \\
\hline
\end{tabular}

The values in Table 2 were found by changing the thickness of the dielectric material.

Table 2. Comparison of the dielectric thickness

\begin{tabular}{|l|c|c|c|}
\hline $\begin{array}{c}\text { Dielectic thickness } \\
(\mathrm{mm})\end{array}$ & $\begin{array}{c}\text { Magnitude } \\
(\mathrm{S} 11: \mathrm{dB})\end{array}$ & $\begin{array}{c}\text { Resonance } \\
\text { Freq.(GHz) }\end{array}$ & Gain(dB) \\
\hline \multirow{3}{*}{$1 \mathrm{~mm}$} & -6.88 & 11 & 8.25 \\
\cline { 2 - 4 } & -37.12 & 11.9 & 4.82 \\
\cline { 2 - 4 } & -29.49 & 15.7 & 7.07 \\
\hline \multirow{3}{*}{$1,2 \mathrm{~mm}$} & -9.32 & 11 & 7.06 \\
\cline { 2 - 4 } & -13.26 & 11.9 & 5.41 \\
\cline { 2 - 4 } & -27.88 & 15.6 & 6.38 \\
\cline { 2 - 4 } & -7.24 & 15.7 & 5.70 \\
\hline \multirow{3}{*}{$1,6 \mathrm{~mm}$} & -10.85 & 11 & 5.08 \\
\cline { 2 - 4 } & -8.71 & 11.9 & 4.81 \\
\cline { 2 - 4 } & -6.06 & 15.7 & 6.31 \\
\hline
\end{tabular}

Table 3 has the results when slots sizes were changed.

Table 3. Parameter value changes with four design steps

\begin{tabular}{|c|c|c|c|}
\hline Design Steps & $\begin{array}{c}\text { Magnitude } \\
(\mathrm{S} 11: \mathrm{dB})\end{array}$ & $\begin{array}{c}\text { Resonance } \\
\text { Freq.(GHz) }\end{array}$ & Gain(dB) \\
\hline \multirow{3}{*}{1} & -6.88 & 11 & 8.25 \\
\cline { 2 - 4 } & -37.12 & 11.9 & 4.82 \\
\cline { 2 - 4 } & -29.49 & 15.7 & 7.07 \\
\hline \multirow{3}{*}{2} & -5.41 & 11 & 8.41 \\
\cline { 2 - 4 } & -13.63 & 11.9 & 1.73 \\
\cline { 2 - 4 } & -17.47 & 11.95 & 5.14 \\
\cline { 2 - 4 } & -18.2 & 15.7 & 4.98 \\
\hline \multirow{6}{*}{3} & -2.18 & 11 & 7.33 \\
\cline { 2 - 4 } & -11.33 & 11.9 & 5.06 \\
\cline { 2 - 4 } & -9.393 & 11.95 & 5.21 \\
\cline { 2 - 4 } & -26.52 & 15 & 10.14 \\
\cline { 2 - 4 } & -1.72 & 15.7 & 6.39 \\
\hline \multirow{5}{*}{4} & -1.96 & 11 & 6.31 \\
\cline { 2 - 4 } & -9.10 & 11.9 & 6.32 \\
\cline { 2 - 4 } & -26.4 & 15.1 & 3.01 \\
\cline { 2 - 4 } & -15.23 & 15.7 & \\
\hline
\end{tabular}


The dielectric constant was changed to see the effect on S11 and gain. The results are shown in Table 4.

Table 4. S11 and gain results with different dielectric constants

\begin{tabular}{|l|c|c|c|}
\hline Dielectic constant & $\begin{array}{c}\text { Magnitude } \\
(\mathrm{S} 11: \mathrm{dB})\end{array}$ & $\begin{array}{c}\text { Resonance } \\
\text { Freq.(GHz) }\end{array}$ & Gain(dB) \\
\hline \multirow{4}{*}{4,3} & -6.88 & 11 & 8.25 \\
\cline { 2 - 4 } & -37.12 & 11.9 & 4.82 \\
\cline { 2 - 4 } & -29.49 & 15.7 & 7.07 \\
\hline 4,5 & -5.08 & 11 & - \\
\cline { 2 - 4 } & -17.86 & 11.65 & 4.65 \\
\cline { 2 - 4 } & -2.88 & 11.9 & 7.27 \\
\cline { 2 - 4 } & -19.34 & 15.35 & 8.39 \\
\cline { 2 - 4 } & -3.24 & 15.7 & 8.87 \\
\hline 4,7 & -2.27 & 11 & 2.43 \\
\cline { 2 - 4 } & -18.32 & 11.9 & - \\
\cline { 2 - 4 } & -3.20 & 15.7 & \\
\hline
\end{tabular}

\section{Conclusion}

In this paper a tri resonance multi slot patch antenna has been presented [19]. Different methods for miniaturization of a square microstrip patch were studied and a novel fractal patch with multiple-slots was developed [20]. In this design, a microstrip patch antenna that is desired to run between $11-22 \mathrm{GHz}$ frequency values has been realized. Gains were observed in 3 frequencies. At $11 \mathrm{GHz}$, the gain of the antenna is $8.25 \mathrm{~dB}$, at $11.9 \mathrm{GHz}$ the gain of the antenna is $4.82 \mathrm{~dB}$, and at $15.7 \mathrm{GHz}$ the gain of the antenna is $7.07 \mathrm{~dB}$. However, a supplementary use of such modifications will certainly help in antenna size reduction with a further improved performance [21]. Future developments could be based on the fabrication of the antenna.

\section{References}

[1] J. J. Tiang, M. T. Islam, N. Misran and J.S. Mandeep, Circular Microstrip Slot Antenna For Dualfrequency Rfid Applicatıon. Progress In Electromagnetics Research, Vol. 120, 499-512, 2011.

[2] K. M. Younus, K. H. Sayidmarie, A Tri-Band Frequency Reconfigurable Slot Antenna for Wireless Applications. Aces Journal, Vol. 35, No. 2, 2020.

[3] Md. Samsuzzamana, M. T. Islamb, M. R. I. Faruque, "Dual-band Multi Slot Patch Antenna for Wireless Applications". Journal of telecommunications and information technology. 2013.

[4] S. K. Patel, Y. P. Kosta, "Meandered Multiband Metamaterial Square Microstrip Patch Antenna Design". Waves in Random and Complex Media 22(4):475-487. DOI: 10.1080/17455030.2012.723837, 2012.

[5] S. Mingle, I. Hassoun, "Compact Fractal Slots of Multi-Resonant Patch Antenna Base on Smith Chart Configuration". 10th International Conference on COMmunication Systems \& NETworkSAt: India, 2018.

[6] S. K. Patel and Y. P. Kosta, "Meandered multiband metamaterial square microstrip patch antenna design," Waves in Random and Complex Media, in press, doi: 10.1080/ 17455030.2012.723837, 2012.

[7] K. A. Khan, S. Singh and A. Jha "Single -Layer Single Patch Quad band Antenna for S \&C Band Application” IJISET - International Journal of Innovative Science, Engineering \& Technology, Vol. 2 Issue 7 july 2015

[8] N. Ab. Wahab, Z. B. Maslan, W. N. W. Muhamad and N. Hamzah, "Microstrip Rectangular 4x1 Patch Array Antenna at $2.5 \mathrm{GHz}$ for WiMax Application". Second International Conference on 
Computational Intelligence, Communication Systems and Networks,july, DOI 10.1109/CICSyN.2010.732010.

[9] A. Roy, S. Bhunia "Compact Broad Band Dual Frequency Slot Loaded Microstrip Patch Antenna with Defecting Ground Plane for Wi-MAX and WLAN" International Journal of Soft Computing and Engineering (IJSCE) ISSN: 2231-2307, Volume-1, Issue-6, January 2012.

[10] K.O. Odeyemi, D.O. Akande and E.O. Ogunti "Educational Tool for Rectangular and Circular Microstrip Antenna Design "International Journal of Engineering Research and Technology. ISSN 0974-3154 Volume 5, Number 12012.

[11] M. T. Islam, M. N. Shakib and N. Misran"Broadband E-H Shaped Microstrip Patch Antenna For Wirelss Systems" Progress In Electromagnetics Research, PIER 98, 163,173, 2009.

[12] G. Singh, F. Rajni, F. R. S. Momi, "Microstrip Patch Antenna with Defected Ground Structure for Bandwidth Enhancement”International Journal of Computer Applications(0975-8887) volüme 73No.9,July 2013.

[13] K. O. Odeyemi, D. O. Akande, E. O. Ogunti“Design of an S-Band Rectangular Microstrip Patch Antenna” European Journal of Scientific Research ISSN 1450-216X Vol.55 No.1, 2011.

[14] P.Subbulakshmi, R.Rajkumar"Design and Characterization of Corporate Feed Rectangular Microstrip Patch Array Antenna”. International Conference on Emerging Trends in Computing, Communication and Nanotechnology, 2013.

[15] K. T. Ahmed, B. Hossain, and J. Hossain, "Designing a high bandwidth Patch Antenna and comparison with the former Patch Antennas" Canadian Journal on Multimedia and Wireless Networks Vol. 2, No. 2, April 2011.

[16] M. A. Uddin, J. Hossain, M. H. Kxabir and A. R. Khan, "Designing High Bandwidth Connected E$\mathrm{H}$ and E-Shaped Microstrip Patch Antennas for S-band Communication" International Journal of Computer Science and Information Security, Vol. 13, No. 6, June 2015.

[17] S. Jana, B. Sinhamahapatra, S. Dey, A. Das, B. Datta, M. Mukherjee, S. K. Chowdhury and S. Chatterjee, "Single Layer Monopole Hexagonal Microstrip Patch Antenna for Satellite Television" International Journal of Soft Computing and Engineering (IJSCE) ISSN: 2231-2307, Volume-2, Issue-6, January,2013.

[18] N. Keskin, U. Saka and T. İmeci, "U-Shaped Microstrip Patch Antenna" 28th Annual Review of Progress in Applied Computational Electromagnetics, April 10-14, 2012.

[19] K.-F. Lee, K.M. Luk, "Design of small size wide bandwidth microstrip patch antenna" IEEE Antennas and Propagation Magazine 45(1):75 - 83, 2003.

[20] H. T. Nguyen, S. Noghanian and L. Shafai, "Microstrip patch miniaturization by slots loading". Conference: Antennas and Propagation Society International Symposium, Volume: 1B, 2005.

[21] A. Aggarwal, M. V. Kartikeyan, "Pythagoras Tree: A Fractal Patch Antenna For Mult1-Frequency And Ultra-Wide Band-Width Operations" Progress In Electrompatnaikagnetics Research C, Vol. $16,25,35,2010$. 